\title{
PENGGUNAAN VERBA DOUSHI BENKYOUSURU, MANABU, RENSHUUSURU, DAN NARAU TERHADAP PASANGAN NOMINANYA
}

\author{
Dhaniar Asmarani \\ Japanese Department, Faculty of Humanities, BINUS University \\ Jln. Kemanggisan Ilir III No.45, Kemanggisan-Palmerah, Jakarta Barat 11480 \\ dasmarani@binus.edu
}

\begin{abstract}
Research discusses the different use of Japanese verbs benkyousuru, manabu, renshuusuru, and narau associated with the use of nouns attaching to the verbs. Data corpus was taken from magazine Jakarta Communication Club: Apa Kabar, Vol 50, 2010. The research applied qualitative study using descriptive analysis method. Research aims to give better understanding for Japanese language learners in using the Japanese verbs benkyousuru, manabu, renshuusuru, narau. Besides, the learners can use these verbs properly as well. Result of the research shows that the verbs have different use and also different use of nouns attaching on the verbs.
\end{abstract}

Keywords: verb, benkyousuru, manabu, renshuusuru, narau, noun

\begin{abstract}
ABSTRAK
Penelitian ini membahas tentang perbedaan penggunaan doushi benkyousuru, manabu, renshuusuru, dan narau yang dihubungkan dengan pasangan meishi (kata benda) yang menempel pada beberapa doushi tersebut. Penelitian ini merupakan penelitian kualitatif dengan metode kepustakaan dan mendeskripsikan analisis yang diperoleh. Penelitian bertujuan agar pembelajar bahasa Jepang dapat lebih mengerti penggunaan doushi benkyousuru, manabu, renshuusuru, dan narau dan tidak tertukar dalam penggunaannya. Dari hasil penelitian diketahui perbedaan penggunaan meishi (kata benda) yang menempel dengan doushi benkyousuru, manabu, renshuusuru, dan narau yang diterapkan pada korpus data berupa majalah Jakarta Communication Club: Apa Kabar Vol 50, tahun 2010.
\end{abstract}

Kata kunci: doushi, benkyousuru, manabu, renshuusuru, narau, meishi 


\section{PENDAHULUAN}

Kata kerja (doushi) benkyousuru, manabu, renshuusuru, dan narau memiliki arti yang maknanya mirip dalam bahasa Indonesia, yaitu belajar dan berlatih (Matsuura, 1994). Padahal setiap doushi tersebut memiliki perbedaan baik dari cara penggunaannya, pemasangan dengan kata kerja di depannya, maupun maknanya. Kata kerja (doushi) benkyousuru, manabu, renshuusuru, dan narau sekilas memiliki arti dalam bahasa Indonsesia yang sama, yaitu belajar. Padahal setiap doushi tersebut memiliki perbedaan baik dari cara penggunaannya, pemasangan dengan kata kerja di depannya, maupun maknanya. Kemiripan makna kata tersebut dalam bahasa Jepang disebut ruigigo (sinonim) (Sudjianto dalam Anggraeni, 2012).

Menurut Nomura dan Koike (1992), doushi (verba) adalah salah satu kelas kata dalam bahasa Jepang (Sudjianto, 2004:149). Kelas kata ini dipakai untuk menyatakan aktivitas, keberadaan, atau keadaan sesuatu. Bagi pembelajar bahasa Jepang tingkat dasar tidak mudah untuk menemukan perbedaan tersebut. Sebagai akibatnya, kesalahan penggunaan doushi terjadi dalam penerapan seharihari. Sehubungan dengan itu, penelitian ini menganalisis perbedaan penggunaan berdasarkan dari makna dan kata benda (meishi) yang menempel kepada doushi benkyousuru, manabu, renshuusuru, dan narau. Meishi menurut Matsuoka (2000) dan Hirai (1989) adalah kata-kata yang menyatakan orang, benda, peristiwa, dan sebagainya, tidak mengalami konjugasi, dan dapat dilanjutkan dengan kakujosi (Sudjianto, 2004:157). Lebih lanjut, meishi adalah kata-kata yang menyatakan nama suatu perkara, benda, barang, kejadian atau peristiwa, keadaan, dan sebagainya yang tidak mengalami konjugasi.

Pada penelitian ini penulis melihat makna dari doushi benkyousuru, manabu, renshuusuru, dan narau, terutama makna denotasi dan konotasinya. Rumpun ilmu dalam lingustik yang mempelajari mengenai arti atau makna adalah semantik (Verhaar, 1996). Makna kata dalam Semantik dibagi menjadi dua, yaitu makna yang bersifat denotatif dan makna yang bersifat konotatif (Keraf, 2007:2728). Kata yang tidak mengandung makna atau perasaan-perasaan tambahan disebut kata denotatif atau maknanya disebut denotatif. Sedangkan makna kata yang mengandung arti tambahan, perasaan tertentu, atau nilai rasa tertentu di samping makna dasar yang umum dinamakan makna konotatif.

Pendapat Keraf (2007) mengenai pembagian makna menjadi makna denotatif dan konotatif ini diperkuat Chaer (2003). Chaer (2003:289) mengelompokkan tipe makna berdasarkan beberapa bagian, salah satunya berdasarkan ada tidaknya nilai rasa pada sebuah kata atau leksem, makna dapat dibedakan menjadi makna denotatif dan konotatif. Menurut Keraf (2007), makna denotatif juga disebut juga dengan beberapa istilah seperti makna denotatifonal, makna kognitif, makna konseptual, makna ideasional, makna refensial, atau makna proporsional. Disebut makna denotatifonal, referensial, konseptual, atau ideasional karena makna itu menunjuk (denote) kepada suatu referen, konsep, atau ide tertentu dari suatu referen. Disebut makna kognitif karena karena makna itu bertalian dengan kesadaran atau pengetahuan; stimulus (dari pihak pembicara) dan respons (dari pihak pendengar) mengangkat hal-hal yang dapat diserap pancaindra (kesadaran) dan rasio manusia. Makna ini juga disebut makna proporsional karena bertalian dengan informasi atau pertanyaan-pertanyaan yang bersifat faktual. Makna ini yang diacu dengan bermacam-macam nama adalah makna yang paling dasar pada suatu kata.

Sementara pengertian makna konotatif menurut Keraf (2007:29) disebut juga makna konotatifonal, makna emotive, atau makna evaluative. Makna evaluative adalah suatu jenis makna yang mana stimulus dan respons mengandung nilai-nilai emosional. Makna konotatif sebagian terjadi karena pembicara ingin menimbulkan perasaan setuju-tidak setuju, senang-tidak senang, dan sebagainya pada pihak pendengar. Di pihak lain, kata yang dipih itu memperlihatkan bahwa pembicara juga memendam perasaan yang sama. 
Penelitian mengambil korpus data doushi benkyousuru, manabu, renshuusuru, dan narau dari artikel Bulletin Jakarta Communication Club Apa Kabar? No. 50 Tahun 2010. Penggunaan doushi dihubungkan dengan penggunaan meishi yang menempel pada doushi benkyousuru tersebut. Penelitian bertujuan untuk menemukan perbedaan dalam penggunaan doushi benkyousuru, manabu, renshuusuru, dan narau terhadap meishi yang menempel pada doushi tersebut. Penelitian diharapkan dapat bermanfaat bagi pembelajar bahasa Jepang dasar. Pembelajar diharapkan mengetahui perbedaan penggunaan doushi terhadap meishi yang menempel pada doushi tersebut yang terdapat pada Bulletin Jakarta Communication Club Apa Kabar? No.50, tahun 2010.

\section{METODE}

Penelitian menggunakan metode deskriptif analitis. Metode deskriptif analitis merupakan metode yang digunakan untuk mengumpulkan informasi mengenai status suatu gejala yang ada, yaitu keadaan gejala secara apa adanya pada saat penelitian dilakukan. Tujuan dari metode ini adalah untuk membuat penjelasan secara sistematis, faktual, dan akurat mengenai fakta-fakta fenomena tertentu. Kemudian, untuk mengumpulkan data, penulis menggunakan korpus data kualitatif berupa artikel dari Bulletin Jakarta Communication Club Apa Kabar? No. 50, Tahun 2010.

\section{HASIL DAN PEMBAHASAN}

Arti dari kata benkyousuru diambil dari dua sumber, yaitu dari kamus Kojien (Shinmura, 1998) dan kamus Kojien Online pada situs: http://dictionary.goo.ne.jp/. Menurut kedua sumber ini, doushi benkyousuru memiliki 2 makna denotatif dan 2 makna konotatif. Makna denotatif dari doushi benkyousuru adalah sebagai berikut:

1.「精を出してつとめること」

(sei o dashite tsutomeru koto)

Arti: Berusaha dengan mengeluarkan/menggunakan energi

2.「学問や技術を学ぶこと。様々な経験を積んで学ぶこと」 (gakumon ya gijutsu o manabu koto. Sama zama na keiken o tsunde manabu koto)

Arti: Mempelajari ilmu atau teknik tertentu. Belajar dengan mengumpulkan pengalaman.

Contoh:

- 「数学を勉強する」

(suugaku o benkyou suru)

Arti: Belajar matematika.

・「あの子にはいい勉強だ」

(ano ko ni wa ii benkyou da)

Arti: Ini adalah pelajaran yang baik untuk anak itu.

Makna konotatif dari benkyousuru dalah sebagai berikut:

1.「商品を安く売ること」Atau「值段をまける」

(shouhin o yasuku uru koto) atau (nedan wo makeru)

Arti: Menurunkan harga barang untuk dijual. 
Contoh:

・「お值段は勉強しときます」 (onedan wa benkyou shitokimasu) Arti: Harganya sudah diturunkan.

・「500 円勉強できませんか」 (500 en benkyou dekimasenka) Arti: Bisakah harganya diturunkan 500 yen?

- 「2000円に勉強しましょう」 (2000 en ni benkyoushimashou) Arti: Saya akan menurunkan harganya menjadi 2000 yen.

\section{2. 勤勉(kinben)}

Arti: Kerajinan, ketekunan, kerja keras.

Contoh:

・「こんな夜遅くまでお仕事とはなかなかご勉強ですね」

(konna yoru osoku made oshigoto wa nakanaka gobenkyou desune.)

Arti: Kamu sungguh tekun sekali, bekerja hingga larut malam seperti ini.

Jika makna denotatif dan konotatif dari doushi Benkyou Suru di ringkas dalam bentuk tabel, maka akan menjadi seperti Tabel 1.

Tabel 1 Makna dari Doushi Benkyou Suru

\begin{tabular}{|c|c|}
\hline Denotatif & Konotatif \\
\hline $\begin{array}{l}\text { 精を出してつとめること } \\
\text { sei o dashite tsutomeru koto } \\
\text { 学問や技術を学ぶこと。様々な経験を積んで学ぶこと } \\
\text { gakumon ya gijutsu o manabu koto. Sama zama na keiken o } \\
\text { tsunde manabu koto }\end{array}$ & $\begin{array}{l}\text { 商品を安く売ること atau值段をまける } \\
\text { shouhin o yasuku uru koto atau nedan wo } \\
\text { makeru } \\
\text { 勤勉 } \\
\text { kinben }\end{array}$ \\
\hline
\end{tabular}

Pada korpus data (Bulletin Jakarta Communication Club Apa Kabar? No. 50) terdapat tiga kalimat yang menggunakan kata kerja Benkyousuru, yaitu:

1.「インドネシアの習慣や文化について勉強しました」

(Indonesia no shuukan ya bunka nitsuite benkyou shimashita)

(diambil dari artikel インドネシア生活セミナーSeminar Kehidupan Indonesia untuk Orang Jepang, halaman 1 ).

Arti: mempelajari mengenai budaya dan kebiasaan masyarakat Indonesia.

2.「東南アジアのことが勉強したかった」

(tounan ajia no koto ga benkyou shitakatta)

(diambil dari artikel インドネシアにこの人あり Tokoh Masyarakat Indonesia, halaman 2).

Arti: (dahulu) ingin mempelajari mengenai Asia Tenggara.

3.「日本語を勉強します」

(nihongo o benkyoushimasu)

(diambil dari artikel 受講生の声Opini dari Murid, halaman 3).

Arti: mempelajari bahasa Jepang. 
Dari ketiga contoh tersebut, dengan melihat kata benda yang dapat digunakan dengan kata kerja benkyousuru, arti dari kata benkyousuru itu sendiri yang paling mendekati adalah arti denotatif dari doushi benkyousuru pada nomor 2, yaitu:

「学問や技術を学ぶこと。様々な経験を積んで学ぶこと」]

(gakumon ya gijutsu wo manabu koto. Sama zama na keiken o tsunde manabu koto)

Arti: Mempelajari ilmu atau teknik tertentu. Belajar dengan mengumpulkan pengalaman.

Untuk memastikan apakah kata benda shuukan, bunka, tounan ajia, dan nihongo termasuk dalam golongan gakumon atau tidak, penulis memeriksa lebih lanjut mengenai arti dari kata gakumon itu sendiri. Arti dari kata Gakumon menurut kamus Kojien adalah:
「一定の理論に基づいて体系化された知識と方法。．史学．文学．社会科学
·自然科学などの総称。学。」
(ittei no riron ni motodzuite taikeika sareta chishiki to houhou. Rekigaku. Bungaku.
Shakaikagaku. Shizenkagaku nado no soushou. Gaku.)
Arti: ilmu tertentu yang tersistemasi dan berdasarkan teori. Contohnya ilmu filsafat, ilmu sejarah, ilmu kesusastraan, ilmu kemasyarakatan, ilmu lingkungan, dan lain-lain.

Dengan mengacu pada arti dari kata gakumon tersebut, dapat diambil simpulan bahwa pada kata benda pada korpus data yaitu: shuukan, bunka, tounan ajia, dan nihongo adalah termasuk gakumon, yang diklasifikasikan sebagai berikut: shuukan, bunka, dan tounan ajia termasuk dari gakumon berjenis社会科学 (shakaikagaku); nihongo termasuk dari gakumon berjenis文学 (bungaku).

Kata manabu diambil dari kojien online pada situs: http://dictionary.goo.ne.jp/. Menurut sumber ini, manabu memiliki 4 arti atau makna denotatif, di antaranya adalah:

1.「勉強する。学問をする」

(benkyou suru. Gakumon o suru)

Arti: Belajar. Menuntut (mempelajari, belajar) ilmu.

Contoh:

-「大学で心理学を学ぶ」

(daigaku de shinri gaku o manabu)

Arti: belajar ilmu psikologi di unversitas

2.「教えを受けたり見習ったりして、知識や技芸を身につける。習得する」

(oshie o uketari minarattari shite, chishiki ya gigei o mi ni tsukeru. Shuutoku suru.)

Arti: Meniru / mempelajari dari suatu sumber untuk dijadikan ilmu bagi dirinya sendiri.

Contoh:

・「彼からフランス語を学んだ」

(kare kara furansu go o mananda)

Arti: belajar bahasa prancis dari dia (laki-laki).

3.「経験することによって知る」

(keiken suru koto ni yotte shiru)

Arti: mengetahui / belajar sesuatu dari pengalaman.

Contoh:

・「苦労して人間のすばらしさを学んだ」

(kurou shite ningen no subarashisa o mananda)

Arti: Belajar dari pengalaman pahit seseorang. 
4.「まねをする」

(mane o suru)

Arti: Meniru, menirukan, mengikut.

Contoh:

- -「先輩に学ぶ」

(senpai ni manabu)

Arti: Mencontoh dari kakak kelas

Jika dibuat dalam bentuk tabel, akan menjadi seperti Tabel 2.

Tabel 2 Makna Denotatif dari Doushi Manabu

勉強する。学問をする
benkyou suru. Gakumon o suru
教えを受けたり 見習ったりして、知識や技芸を身につける。習得するgakumon ya
gijutsu o oshie o uketari minarattari shite, chishiki ya gigei o mi ni tsukeru. Shuutoku suru
経験することによって知る
keiken suru koto ni yotte shiru
まねをする
mane o suru

Kata Renshuusuru diambil dari dua sumber, yaitu kamus Kojien (Shinmura, 1998) dan kamus Kojien Online pada situs: http://dictionary.goo.ne.jp/. Menurut 2 sumber ini, renshuusuru mempunyai arti berupa 4 makna denotatif, yaitu:

1.「学問. 技芸などの上達を目標に、繰り返して習うこと。練習。」 (gakumon. Gigei nado no joutatsu o mokuhyou kurikaeshite narau koto. Renshuu.)

Arti: ilmu atau seni yang dipelajari secara berulang-ulang untuk mencapai kemajuan target.

Contoh:

・「ピアノを練習する」

(piano o renshuu suru)

Arti: berlatih bermain piano

2.「体力増強のための運動や知識訓練」

(tairyoku zoukyou no tame no undou ya chishiki kunren)

Arti: berlatih untuk meningkatkan kekuatan fisik.

3.「体力、技術を伸ばすために練習された訓練すること」

(tairyoku. Gijutsu o nobasu tame ni renshuu sareta kunren suru koto)

Arti: berlatih untuk mengembangkan teknik atau kekuatan.

4.「指導のもとに反復して訓練すること」

(shidou no moto ni hanpuku shite kunren suru koto)

Arti: berlatih dengan cara berulang-ulang, dengan menggunakan bimbingan sesorang.

Jika dibuat dalam bentuk tabel, akan menjadi seperti Tabel 3. 
Tabel 3 Makna Denotatif dari Doushi Renshuu Suru

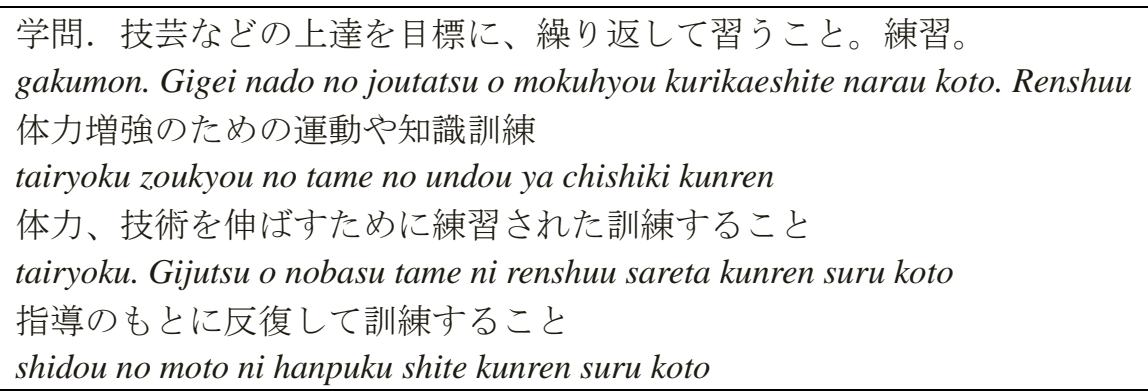

Arti dari kata narau diambil dari kamus Kojien Online pada situs: http://dictionary.goo.ne.jp/. Menurut 2 sumber tersebut, narau memiliki tiga makna denotatif, di antaranya adalah:

1.「教わったことを繰り返し練習して身につける。稽古する」

(osowatta koto o kurikaeshi renshuu shite mi ni tsukeru. Keiko suru.)

Arti: hal yang telah dipelajari, dipelajari kembali berulang-ulang untuk diri sendiri.

Contoh:

・「夜更けに一人でダンスのステップを習う」

(yofuke ni hitori de dansu no suteppu wo narau)

Arti: Mempelajari sendiri langkah tarian sampai larut malam

2.「知識や技術などの教えを受ける。教わる。学ぶ」

(chishiki ya gijutsu nado no oshie o ukeru. Osowaru. Manabu.)

Arti: mendapat ajaran mengenai ilmu atau teknik dari orang lain.

Contoh:

-「父から将棋を習う」

(chichi kara shougi o narau)

Arti: Belajar catur Jepang dari ayah

3.「経験を積んで、習う。習慣となる」

(keiken o tsunde, narau. Shuukan to naru.)

Arti: belajar dari pengalaman. Menjadi kebiasaan.

Jika dibuat dalam bentuk tabel, akan menjadi seperti Tabel 4 .

Tabel 4 Makna Denotatif dari Doushi Narau

\begin{tabular}{l}
\hline 教わったことを繰り返し練習して身につける。稽古する \\
osowatta koto o kurikaeshi renshuu shite mi ni tsukeru. Keiko suru \\
知識や技術などの教えを受ける。教わる。学ぶ \\
chishiki ya gijutsu nado no oshie o ukeru. Osowaru. Manabu \\
経験を積んで、習う。習慣となる \\
keiken o tsunde, narau. Shuukan to naru \\
\hline
\end{tabular}




\section{SIMPULAN}

Setelah menganalisis makna denotatif dan konotatif mengenai keempat doushi tersebut (benkyousuru, menabu, renshuusuru, dan narau), dapat diambil simpulan sebagai berikut. Pertama, doushi benkyousuru digunakan untuk mempelajari suatu ilmu/teknik dalam arti umum. Oleh karena itu, meishi yang dapat dipasangkan dengan doushi benkyousuru adalah meishi yang mempunyai makna suatu ilmu atau teknik tertentu secara umum. Kedua, doushi renshuusuru digunakan untuk menunjukkan seseorang yang berlatih secara berulang-ulang untuk mencapai suatu tujuan tertentu. Maka dari itu meishi yang dipasangkan dengan doushi renshuusuru, jika dilihat dari segi kalimat (sintaksis), memiliki makna sesuatu yang dilatih berulang-ulang untuk mencapai tujuan tertentu. Ketiga, doushi darau digunakan ketika mendapat ilmu/pengajaran dari seseorang. Atau, belajar dari orang; ada orang yang mengajari. Oleh sebab itu, meishi yang dipasangkan dengan doushi narau, jika dilihat dari segi kalmat (sintaksis), menjadi bermakna belajar suatu ilmu dari orang lain. Keempat, doushi manabu memiliki arti yang hampir sama dengan doushi benkyousuru, yaitu digunakan untuk mempelajari suatu bidang ilmu/teknik dalam arti umum. Akan tetapi, terdapat 1 point yang membedakan doushi manabu dengan benkyousuru, yaitu manabu juga memiliki arti belajar dari pengalaman yang terjadi pada orang lain untuk diterapkan pada diri sendiri.

\section{DAFTAR PUSTAKA}

Anggraeni, Y. (2012). Analisis penggunaan ureshii, tanoshii, dan yorokobu dalam kalimat bahasa Jepang. Chi'e: Journal of Japanese Learning and Teaching, 1(1), 7-9. Available at http://journal.unnes.ac.id/sju/index.php/chie/article/viewFile/331/380

Chaer, A. (2003). Linguistik Umum. Jakarta: Rineka Cipta.

Hirai, M. (1989). Nandemo Wakaru Shinkokugo Handobukku. Tokyo: Sanseido.

Jakarta Communication Club. (2010). Jakarta Communication Club Apa Kabar? No. 50. Bulletin Jakarta: Bagian Pemasaran Jakarta Communication Club.

Keraf, G. (2007). Diksi dan Gaya Bahasa. Jakarta: Gramedia Pustaka Utama.

Matsuoka, H. (2000). Shokyuu o Oshieru Hito no Tame no Nihongo Bunpoo Handobukku. Tokyo: Suriee Nettowaaku

Matsuura, K. (1994). Kamus Jepang-Indonesia. Jakarta: Gramedia Pustaka Utama.

Nomura, M., \& Koike, S. (1992). Nihongo Jiten. Tokyo: Tosho Insatsu.

Shinmura, I. (1998). Koujien. Tokyo: Iwanami Shoten.

Sudjianto (2004). Pengantar Linguistik Bahasa Jepang. Bekasi: Kesaint Blanc

Verhaar, J. W. M. (1996). Asas-asas Linguistik Umum. Yogyakarta: Gadjah Mada University Press. 